\title{
PENINGKATAN GENERATIVITAS MELALUI TERAPI KELOMPOK PADA PEREMPUAN PARUH BAYA
}

\author{
Hapsah $^{1,2^{*}}$, Achir Yani S. Hamid ${ }^{3}$, Herni Susanti ${ }^{3}$ \\ 1. Program Studi Ilmu Keperawatan Universitas Hasanudin, Makassar 90245 , Indonesia \\ 2. Program Studi Magister Fakultas Ilmu Keperawatan Universitas Indonesia, Depok 16424, Indonesia \\ 3. Fakultas Ilmu Keperawatan Universitas Indonesia, Depok 16424, Indonesia \\ *Email: hapsah_hhj@yahoo.com
}

\begin{abstract}
Abstrak
Perempuan paruh baya mengalami banyak perubahan psikososial yang dapat mempengaruhi perkembangannya sehingga diperlukan upaya promotif untuk meningkatkan derajat kesehatannya. Penelitian quasi experimental dengan pendekatan prepost test with control group ini ditujukan untuk mengidentifikasi pengaruh terapi kelompok terapeutik (TKT) terhadap perkembangan generativitas perempuan paruh baya di Kabupaten Pinrang. Hasil penelitian terhadap 34 orang kelompok intervensi dan 36 orang kelompok kontrol (melalui purposive sampling) menunjukkan peningkatan generativitas secara bermakna ( $\mathrm{p}=$ $0,000, \alpha=0,05)$ pada kelompok intervensi dan peningkatan secara tidak bermakna pada kelompok kontrol $(p=0,410, \alpha=0,05)$ sebelum dan sesudah dilakukan TKT. Terapi kelompok terapeutik ini direkomendasikan untuk dikembangkan sebagai bentuk pelayanan kesehatan jiwa bagi perempuan paruh baya.
\end{abstract}

Kata kunci: generativitas, perempuan paruh baya, terapi kelompok terapeutik

\begin{abstract}
Middle age women generally experience many phsycosocial changes that can influence their developments, hence they need promoted actions to improve their health quality. This experimental quasi research using pre-post test with control group aims to identify an influence of therapeutic group therapy on the generativity development of middle age women in Pinrang Regency. The results showed that generativity development are significantly higher $(p=0,000, \alpha=0,05)$ on treated group $(n=34)$ compared to control group $(n=36)$ which did not show significant improvement $(p=0,410, \alpha=0,05)$ before and after intervention. This therapeutic group treatment was recommended to be developed as one way to promote mental health for middle age women.
\end{abstract}

Keywords: generativiy, middle age woman, therapeutic group therapy

\section{Pendahuluan}

Kesehatan jiwa merupakan bagian integral dari kesehatan. Tanpa kesehatan jiwa, kesehatan itu sendiri tidak ada. Kesehatan jiwa berhak dimiliki oleh setiap orang. Namun, pelayanan kesehatan masih berorientasi pada kesehatan fisik. Hal ini terbukti dari tujuan pembangunan kesehatan yang dilaksanakan saat ini mengacu pada Undang-undang No. 17 Tahun 2007 tentang Rencana Pembangunan Jangka Panjang Nasional (RPJP-N) Tahun 2005-2025 dengan memberikan perhatian khusus pada penduduk rentan menderita penyakit yaitu ibu, bayi, dan anak, usia lanjut dan keluarga miskin (BPN, 2007).

Pelayanan kesehatan jiwa masih sangat minim dilakukan, dan masih berorientasi pada kelompok yang mengalami gangguan jiwa, sedangkan jumlah kelompok yang tidak mengalami gangguan jiwa jauh lebih besar yaitu kurang lebih berjumlah $87,9 \%$ (setelah dikurangi dengan total penderita gangguan jiwa berat dan gangguan mental emosional) (Riskesdas, 2007).

Mengingat angka ini terus berkurang dari tahun ke tahun seiring dengan makin meningkatnya jumlah penderita gangguan jiwa, maka upaya peningkatan kesehatan jiwa pada masyarakat hendaknya menjadi salah satu fokus pelayanan kesehatan.

Salah satu ciri sehat jiwa adalah mampu untuk tumbuh dan berkembang secara normal (Keliat, et al., 2005) pada tiap tahapan usia termasuk paruh baya. Usia paruh baya berada pada rentang usia 40 - 60 tahun (Levinson, 1978; dalam Berk, 2005). 
Pada usia ini terjadi perubahan psikososial yang kompleks yang bisa mengakibatkan terjadinya krisis paruh baya. Krisis ini merupakan suatu kondisi dimana paruh baya mengalami kesenjangan antara masa lalu dan masa yang akan datang. Paruh baya mempertanyakan tujuan-tujuannya yang belum tercapai dan harus menyesuaikan diri dengan berbagai perubahan yang dialaminya.

Menurut erikson (1964, dalam Berk, 2005), masa paruh baya merupakan tahapan menghadapi konflik antara mencapai generativitas atau mengalami stagnasi. Bila ia sukses menjalankan perkembangannya dengan baik ia akan mencapai generativitas, namun bila gagal akan terserap ke dalam dirinya dan mengalami stagnasi.

Perubahan psikososial yang dialami paruh baya cukup banyak. Terkait gender, perempuan lebih banyak mengalami perubahan psikososial dan memiliki risiko lebih tinggi terkena penyakit fisik dan gangguan jiwa dibanding laki-laki(Papalia, Olds, \& Feldman, 2008; Riskesdas, 2007). Perempuan paruh baya mengalami perubahan peran yang lebih kompleks. Di samping itu, perempuan harus menghadapi masa menopause yang rentan terhadap berbagai macam penyakit.

Data Unit Gawat Darurat Kabupaten Pinrang (RS Kab Pinrang, 2009) menunjukkan angka kejadian penyakit yang berhubungan dengan usia dan stres cukup tinggi pada usia paruh baya yaitu sebesar $56,4 \%$ dari total penderita stroke, $47,5 \%$ dari total penderita gagal jantung, 45,9\% dari total penderita tukak lambung, dan $75 \%$ dari total penderita infark miokard akut serta $53,6 \%$ dari total penderita hipertensi. Berdasarkan data tersebut, bisa dilihat prevalensi kejadian penyakit terjadi pada usia paruh baya. Selain itu, dari data tersebut dilaporkan angka kejadian pada perempuan paruh baya lebih tinggi dari pada laki-laki paruh baya yaitu sebesar $52,3 \%$ dari total paruh baya yang menderita hipertensi dan sebesar 53,2\% dari total paruh baya yang menderita gastritis/ tukak lambung.

Penyakit fisik sebagian besar disebabkan oleh masalah psikososial. Kuat dan lamanya stres yang dialami akibat tekanan psikososial dapat melemahkan sistem imun dan meningkatkan kerapuhan terhadap penyakit.
(Harvard Medical School, 2002 dalam Papalia, Olds, dan Feldman, 2008). Hal ini sejalan dengan penelitian klasik yang menunjukkan $70 \%$ penyakit disebabkan stres atau tekanan hidup (Home \& Rahe, 1976 dalam Papalia, Olds, \& Feldman, 2008).

Berbagai masalah di atas tentu saja dapat dicegah oleh perempuan paruh baya. Adaptasi yang baik terhadap berbagai perubahan yang terjadi dapat dicapai melalui penyelesaian tugas perkembangan di masa tersebut. Tugas perkembangan adalah tugas-tugas yang harus diselesaikan perempuan pada fase-fase atau periode kehidupan tertentu; dan apabila berhasil mencapainya mereka akan berbahagia, tetapi sebaliknya apabila gagal, mereka akan kecewa dan dicela orang tua atau masyarakat dan perkembangan selanjutnya juga akan mengalami kesulitan (Havighurst, 1972 dalam Laraia \& Stuart, 2005).

Generativitas merupakan ciri sehat secara psikologis bagi paruh baya. Beberapa di antara ciri generativitas perempuan paruh baya adalah menerima dan menyesuaikan diri terhadap berbagai perubahan fisik dan fisiologis serta perubahan psikososial yang dialaminya, mampu menghubungkan diri sendiri dengan pasangan hidup sebagai individu dalam dengan meningkatkan keakraban dengan pasangan (ditandai dengan keharmonisan hubungan seksual); menggunakan strategi koping yang efektif dalam memecahkan masalah; membantu anak-anaknya yang telah remaja menjadi orang dewasa yang bertanggung jawab dan berbahagia melalui warisan positif dari dirinya; menjadi nenek yang baik dan bias menjaga dan merawat cucunya; mengembangkan kegiatankegiatan pengisi waktu senggang yang dewasa; mencapai tanggung jawab sosial dan warga Negara secara penuh (Erikson, 1950 dalam Berk, 2005).

Salah satu terapi yang digunakan sebagai pencegahan primer bagi perempuan paruh baya adalah terapi kelompok terapeutik. Terapi ini ditujukan meningkatkan kesehatan perempuan paruh baya dalam pemenuhan kebutuhan perkembangan psikososialnya. Terapi kelompok terapeutik (TKT) merupakan salah satu jenis terapi kelompok yang memberi kesempatan kepada anggotanya untuk saling berbagi pengalaman, 
saling membantu satu dengan lainnya untuk menemukan cara menyelesaikan masalah dan mengantisipasi masalah yang akan dihadapi dengan mengajarkan cara yang efektif untuk mengendalikan stres (Shives, 1998).

Oleh karena itu, penelitian ini dilakukan untuk mengidentifikasi pengaruh terapi kelompok terapeutik (TKT) terhadap perkembangan generativitas perempuan paruh baya di Kabupaten Pinrang. Hal ini penting agar dapat meningkatkan generativitas individu dalam hal ini pada aspek biopsikoseksual, sosial, emosional dan kognitif sehingga perempuan paruh baya dapat menjalani masa paruh baya yang bahagia dan sukses menghadapi tahap perkembangan selanjutnya.

\section{Metode}

Penelitian menggunakan metode quasi experiment dengan desain "pre-post test with control group" dengan melakukan intervensi Terapi Kelompok Terapeutik (TKT) pada tanggal 18 Mei sampai 11 Juni 2010 di Kelurahan Temmassarangnge (intervensi, $\mathrm{n}=34$ ) dan Pacongang (kontrol, $\mathrm{n}=36$ ) Kabupaten Pinrang.

Sampel diperoleh secara purposive sampling yang berusia 40 - 50 tahun, bisa baca tulis, memiliki suami dan anak (masih hidup). Analisis data pooled \& paired t-test, serta analisis korelasi regresi linear sederhana. Kelompok intervensi diberikan TKT sebanyak lima sesi (durasi: 45- 90 menit).

\section{Hasil}

Karakteristik perempuan paruh baya pada kelompok intervensi adalah rata-rata berusia 44 tahun dengan tingkat pendidikan rata-rata SMP sebagian besar tidak bekerja, dan sebagian besar memiliki pendapatan keluarga di bawah Rp1 juta/bulan serta memiliki hubungan sosial yang baik.

Pada responden kelompok kontrol, rata-rata berusia 44,67 tahun dengan tingkat pendidikan rata-rata SD, sebagian besar tidak bekerja, dan sebagian besar memiliki pendapatan keluarga di bawah Rp 1 juta/bulan serta hubungan sosial yang baik.

Hasil analisis pada generativitas perempuan paruh baya sebelum dan sesudah TKT dilakukan pada kelompok intervensi mengalami peningkatan yang signifikan sebesar 3,65 poin $(p=0,000, \alpha=0,05)$. Sedangkan pada kelompok kontrol mengalami peningkatan secara tidak signifikan yaitu sebesar $0,68(p=0,410, \alpha=0,05)$ (lihat tabel 5.18).

Hasil penelitian juga menunjukkan bahwa tidak ada hubungan antara karakteristikusia, tingkat pendidikan, pekerjaan dan pendapatan perempuan paruh baya dengan generativitas perempuan paruh baya sesudah TKT dilakukan baik pada kelompok intervensi maupun kontrol. Sedangkan untuk karakteristik hubungan sosial, ada hubungan yang signifikan dengan generativitas perempuan paruh baya dengan kualitas hubungan adalah sedang (lihat tabel 5.19).

Tabel 5.18 Generativitas Perempuan Paruh Baya pada Kelompok Intervensi Sebelum dan Sesudah Dilakukan TKT

\begin{tabular}{|c|c|c|c|c|c|c|}
\hline & abel & Mean & SD & $\mathbf{S E}$ & $\mathbf{p}$ & $\mathbf{N}$ \\
\hline \multirow{2}{*}{ Generativitas } & Sebelum & 65,76 & 4,264 & 0,731 & \multirow{2}{*}{0,000} & \multirow{2}{*}{34} \\
\hline & Sesudah & 69,41 & 4,321 & 0,741 & & \\
\hline \multicolumn{2}{|c|}{ Selisih Mean : } & 3,65 & & & \multirow{3}{*}{0,410} & \multirow{3}{*}{34} \\
\hline \multirow{2}{*}{ Generativitas } & Sebelum & 64,26 & 5,378 & 0,922 & & \\
\hline & Sesudah & 64,94 & 4,954 & 0,850 & & \\
\hline \multicolumn{2}{|c|}{ Selisih Mean : } & 0,68 & & & & \\
\hline
\end{tabular}




\section{Pembahasan}

Kesimpulan yang dapat diambil, yaitu- ada perbedaan generativitas perempuan paruh baya antara kelompok intervensi dengan kelompok kontrol. Artinya, ada pengaruh terapi kelompok terapeutik terhadap perkembangan generativitas perempuan paruh baya yang ditunjukkan oleh peningkatan generativitas secara signifikan pada kelompok intervensi.Hal ini kemungkinan disebabkan adanya proses belajar melalui pengetahuan dan berbagai keterampilan yang diperoleh dalam pelaksanaan TKT dalam penelitian.

Menurut Notoatmodjo (2003), dengan pemberian informasi akan memberikan pengetahuan pada orang yang mendapatkan informasi tersebut dan menimbulkan kesadaran mereka mengenai pentingnya informasi yang disampaikan dan akhirnya menyebabkan perubahan sikap dan atau perilaku sesuai dengan pengetahuan yang dimilikinya tersebut. Selain itu, informasi juga dapat mempengaruhi persepsi seseorang.

Persepsi sebagian besar perempuan paruh baya sebelum penelitian misalnya, menganggap cara mengatasi stres/masalah yang selama ini mereka gunakan adalah memang demikian seharusnya dan semua orang memecahkan masalah seperti apa yang mereka lakukan. Selain itu, proses dalam kelompok yang memberi kesempatan kepada masing-masing anggota kelompok untuk berbagi pengalaman mengenai perubahan yang terjadi pada usia paruh baya, masalah-masalah yang mungkin timbul, dan saling membantu dalam menemukan cara menyelesaikan masalah serta mengantisipasi masalah yang dihadapi dengan belajar cara efektifmengendalikan stress dalam kehidupan sehari-hari(Townsend, 2009).

Adanya pertukaran informasi antar anggota dalam kelompok memungkinkan perempuan paruh baya mampu memanfaatkan sumber-sumber yang ada dan mencari sumber-sumber baru yang dapat dimanfaatkan sebagai penyelesaian adaptif terhadap berbagai masalah yang dihadapi serta bermanfaat bagi pengembangan diri mencapai generativitasnya.

Latihan yang diberikan pada saat terapi seperti latihan berpikir positif, penyelesaian masalah yang adaptif, relaksasi, latihan kognitif, dan latihan komunikasi kemungkinan besar menjadi faktor yang sangat berpengaruh pada peningkatan generativitas perempuan paruh baya setelah terapi selesai dilakukan.

Usia berbanding lurus dengan kondisi kedewasaan baik fisik maupun psikologis. Hal ini sejalan dengan pernyataan Siagian (1995) bahwa semakin lanjut usia seseorang semakin meningkat pula kedewasaan teknis dan tingkat kedewasaan psikologisnya yang menunjukkan kematangan jiwa, dalam arti semakin bijaksana, mampu berpikir secara rasional, mengendalikan emosi dan bertoleransi terhadap orang lain.

Tabel 5.19 Hubungan Karaktersitik Perempuan Paruh Baya pada Kelompok Intervensi dan Kontrol Sesudah Dilakukan TKT

\begin{tabular}{|c|c|c|}
\hline Jenis variabel & Kelompok & $\mathbf{p}$ \\
\hline \multirow{2}{*}{ Usia } & kontrol & 0,262 \\
\hline & Intervens i & 0,968 \\
\hline \multirow{2}{*}{ Tingkat pendidikan } & kontrol & 0,275 \\
\hline & Intervens i & 0,554 \\
\hline \multirow{2}{*}{ Pekerjaan } & kontrol & 0,827 \\
\hline & Intervens i & 0,373 \\
\hline \multirow{2}{*}{ Pendapatan } & kontrol & 0,148 \\
\hline & Intervens i & 0,206 \\
\hline \multirow{2}{*}{ Hubungan sosial } & kontrol & 0,037 \\
\hline & Intervens $\mathrm{i}$ & 0,012 \\
\hline
\end{tabular}


Menurut Papalia, Olds, dan Feldman (2008), semakin tua umur seseorang maka semakin generatif pula perilakunya. Menurut Hurlock (1998), pada kondisi normal, semakin cukup usia maka tingkat kematangan dan kekuatan seseorang semakin meningkat, baik itu dalam berpikir maupun dalam bekerja.

Pernyataan tersebut tidak sejalan dengan hasil penelitian. Menurut asumsi peneliti, pengalaman dan pola hidup yang dipelajari dari lingkungan yang sama dan mengakibatkan perempuan paruh baya memiliki perilaku yang tidak jauh berbeda dalam mengatasi masalah kehidupan sehari-hari dimana hal tersebut sangat terkait dengan sikap/perilaku generativitas.

Papalia, Olds, dan Feldman, (2008) menyatakan tingkat pendidikan merupakan salah satu faktor yang berpengaruh terhadap pencapaian tugas perkembangan tersebut. Hal ini didukung oleh pendapat yang dikemukakan oleh Stuart dan Laraia (2005) bahwa pendidikan menjadi salah satu tolak ukur kemampuan seseorang dalam berinteraksi dengan orang lain secara efektif.

Tingkat pendidikan juga tidak berhubungan dengan generativitas perempuan paruh baya. Padahal, menurut Papalia, Olds, dan Feldman (2008), tingkat pendidikan merupakan salah satu faktor yang berpengaruh terhadap pencapaian tugas perkembangan tersebut. Hal ini didukung oleh Stuart dan Laraia (2005) bahwa pendidikan menjadi salah satu tolak ukur kemampuan seseorang dalam berinteraksi dengan orang lain secara efektif.

Hasil penelitian tidak sejalan dengan pendapat teoritis di atas. Menurut asumsi peneliti, pendidikan formal sebagian besar ilmu yang dipelajari adalah mengenai ilmu fisik dan hanya sebagian kecil bahkan sangat jarang sekali yang mengajarkan tentang ilmu pengembangan diri.

Hal tersebut seperti cara penyelesaian masalah, cara menghadapi stres, cara mendidik anak secara tepat agar menjadi manusia dewasa yang mandiri dan siap menghadapi tantangan hidup secara adaptif dan lain sebagainya. Hal ini menjelaskan walaupun tingkat pendidikan seseorang hanya SD atau SMP bila ia memiliki pengetahuan dan kemampuan tentang semua itu, bisa saja memiliki nilai generativitas yang jauh lebih tinggi dari mereka yang memiliki tingkat pendidikan yang lebih tinggi.

Karakteristik lain yang tidak berhubungan dengan generativitas perempuan paruh baya adalah pekerjaan. Menurut (Hawari, 2001), masalah pekerjaan merupakan sumber stres pada diri seseorang yang bila tidak dapat diatasi yang bersangkutan dapat jatuh sakit. Semakin tinggi beban stres seseorang maka ia semakin sulit untuk menjalankan tugas perkembangannya dengan baik (Berk, 2005).

Riset membuktikan, baik yang bekerja maupun tidak bekerja dapat mengalami beban stres yang tinggi (Papalia, Olds, \& Feldman, 2008). Berdasarkan hal tersebut, peneliti berasumsi apapun status pekerjaan responden baik bekerja maupun tidak bekerja, bila mereka tidak memiliki perkembangan diri yang baik, maka nilai generativitas mereka tentunya sebagian besar adalah sama.

Karakteristik pendapatan juga tidak memiliki hubungan dengan generativitas perempuan paruh baya. Orang dengan pendapatan yang lebih rendah memiliki harapan hidup yang lebih rendah pula, memiliki banyak keterbatasan aktivitas dikarenakan penyakit kronis, kesejahteraan yang lebih rendah dan memiliki akses yang lebih terbatas kepada perawatan kesehatan ketimbang orang dengan pendapatan yang lebih tinggi (Spiro, 2002 dalam Papalia, Olds, \& Feldman, 2008).

Depkes (2007) juga memiliki pendapat orang yang memiliki pendapatan rendah akan membatasi dirinya untuk melakukan upaya peningkatan kesehatan dibanding yang berpendapatan tinggi. Hal ini disebabkan oleh alasan yang bersifat psikososial dimana orang-orang dengan pendapatan tinggi cenderung memiliki kepekaan yang lebih besar terhadap apa yang terjadi pada tubuh mereka ketika usia mereka semakin bertambah, dan mereka bisa memilih gaya hidup yang lebih sehat (Whitbourne, 2001 dalam Papalia, Olds, \& Feldman, 2008). 
Berdasarkan pernyataan tersebut, peneliti berasumsi orang yang memiliki tingkat pendapatan lebih tinggi memang lebih cenderung memiliki kepekaan terhadap tubuhnya, artinya masalah kesehatan fisik yang cenderung lebih mereka perhatikan dibanding masalah kesehatan jiwa mereka. Padahal, kesehatan itu tidak akan terwujud tanpa kesehatan jiwa. Sehingga, tidak sedikit kita dapati di masyarakat, orang yang memiliki tingkat pendapatan tinggi dengan kondisi perkembangan psikososial terganggu.

Penelitian lain juga membuktikan pada tingkat hubungan sosial yang baik (termasuk dukungan sosial) menunjukkan status kesehatan dan perkembangan psikis yang lebih baik (penelitian terhadap 695 perempuan dan laki-laki dewasa oleh Choi dan Wodarski, 1996). Hal ini juga sejalan dengan pendapat Mireault dan de Man (1996) yang mengatakan sebagian besar orang yang bunuh diri saat usia yang sudah matang sangat berhubungan dengan isolasi sosial yang tinggi dan ketidakpuasan terhadap kesehatan dan dukungan sosialnya. Artinya perkembangan jiwa seseorang sangat terkait dengan kualitas dan kepuasan terhadap hubungan sosial yang dijalaninya. Gejala yang menyimpang dari generativitas atau mengalami stagnasi bisa erat kaitannya dengan ketidakpuasan dalam hubungan sosial.

Hasil penelitian sejalan dengan teori yang ada. Menurut asumsi peneliti, hubungan sosial yang baik dapat mencerminkan penerimaan diri perempuan paruh baya terhadap orang lain dan penerimaan orang lain terhadap diri perempuan paruh baya. Keharmonisan hubungan dengan pasangan misalnya, akan sangat memberikan kontribusi terhadap perkembangan paruhbaya. Bila hubungan tersebut terjalin dan dapat dipertahankan oleh paruh baya, keutuhan itu menjadi panutan bagi generasi berikutnya sebagai warisan yang positif. Sehingga, juga akan berlanjut secara turun temurun.

\section{Kesimpulan}

Karakteristik perempuan paruh baya pada kelompok intervensi dan kontrol hanya berbeda pada rata-rata usia yaitu 44 tahun (kelompok intervensi) dan 44,67 tahun (kelompok kontrol). Sedangkan karakteristik yang lain sama yaitu, tingkat pendidikan rata-rata rendah (SD, SMP), rata-rata tidak bekerja, dan ratarata memiliki pendapatan keluarga di bawah Rp1 juta/ bulan serta rata-rata hubungan sosial baik.

Generativitas perempuan paruh baya sebelum dilakukan TKT pada intervensi lebih tinggi yaitu 65,76 daripada kelompok kontrol yaitu 64. Namun keduanya dalam rentang nilai generativitas yang cukup tinggi. Karakteristik usia, tingkat pendidikan, pekerjaan dan pendapatan perempuan paruh baya tidak berhubungan dengan generativitas perempuan paruh baya sesudah TKT dilakukan baik pada kelompok yang mendapatkan TKT maupun yang tidak mendapatkan TKT. Namun demikian, terdapat hubungan karakteristik hubungan sosial (dukungan sosial, sumber stres dan sumber koping) dengan generativitas perempuan paruh baya sesudah TKT dilakukan baik pada kelompok intervensi maupun kontrol dengan kualitas hubungan adalah sedang.

Saran peneliti berdasarkan hasil penelitian antara lain Depkes RI sebagai lembaga tertinggi di bidang kesehatan sebaiknya membuat kebijakan baru agar program pelayanan kesehatan jiwa masyarakat dapat berdiri sendiri tanpa terintegrasi dengan program kesehatan lain di Puskesmas. Hal ini agar pelayanan kesehatan jiwa masyarakat bisa lebih optimal dilaksanakan dan dapat mendukung terwujudnya Indonesia sehat 2025. Terapi kelompok terapeutik ini selayaknya dijadikan sebagai standar kompetensi bagi perawat jiwa yang disertifikasi oleh organisasi profesi melalui kolegium keperawatan jiwa.

Bagi perawat jiwa di masyarakat, sekiranya dapat melakukan sosialisasi hasil penelitian. Sosialisasi penting agar masyarakat mengetahui pentingnya upaya peningkatan kesehatan jiwa bagi perempuan usia paruh baya melalui TKT. Selain itu, penelitian lain hendaknya dilakukan terhadap para perawat Puskesmas di Kabupaten Pinrang mengenai TKT perempuan paruh baya di wilayah kerja masingmasing. Penelitian dapat dilakukan dengan merangkul peneliti lain, institusi pendidikan dan organisasi profesi melalui kolegium keperawatan jiwa (DN, AY, YA). 


\section{Referensi}

Badan Pembangunan Nasional. (2007). Undangundang Republik Indonesia nomor 17 tahun 2007 tentang rencana pembangunan jangka panjang nasional tahun 2005 - 2025. Diperoleh dari http://www.bappenas.go.id/ get-file-server/node/84/.

Berk. (2005). Development through the life span (2th ed.). USA: Allyn \& Bacon.

Choi, N., \& Wedarski, J. (1996). Relationship between social support and the health status of elderly people. Diperoleh dari http://www.apa.org/ monitor/jan00/cs.aspx.

Depkes RI. (2007). Pembangunan kesehatan bertujuan untuk meningkatkan kesadaran. Diperoleh dari www.depkes.go.id/downloads/ profil/prov\%20lampung\%202007.pdf

Hawari, D. (2001). Pendekatan holistik pada gangguan jiwa skizoprenia. Jakarta : FKUI.

Hurlock, E. (1998). Children language acquasition. Journal of Social Psychology \& Personality, 9 (23). Washington DC: American Psychological Association.

Keliat, B.A., et al. (2005). Modul basic course community health nursing (Tidak dipulikasikan). Jakarta: FIK UI.

Mireault, M., \& de Man, A.F. (1996). Suicidal ideation among the elderly: Personal variables, stress, and social support. Social Behavior and Personality: An International Journal, 24 (4), 385-392.

Notoatmodjo, S. (2003). Pendidikan dan perilaku kesehatan. Jakarta: Rineka Cipta.

Papalia, D.E., Old, S.W., \& Feldman, R.D. (2008). Human development (9th Ed.). Jakarta: Kencana.

Riset Kesehatan Dasar (Riskesdas). (2007). Laporan nasional 2007. Badan Penelitian dan Pengembangan Kesehatan Departemen Kesehatan, Republik Indonesia. Jakarta: Depkes.

Rumah Sakit Kabupaten Pinrang. (2009). Data Unit Gawat Darurat Kabupaten Pinrang. Rumah Sakit Kabupaten Pinrang, Makassar.

Siagian, S.P. (1995). Teori, motivasi, dan aplikasinya (Cet. II). Jakarta: Rineka Cipta.

Shives, L.R. (1998). Basic concepts of psychiatricmental health nursing (4th Ed.). Philadelphia: Lippincott.

Stuart, G.W., \& Laraia, M.T. (2005). Principles and practice of psychiatric nursing (8th Ed.). St Louis: Mosby.

Townsend. (2009). Essentials of psychiatric mental health nursing (5th Ed.). Philadelphia: F.A. Davis Company.

Karena manusia cinta akan dirinya, tersembunyilah baginya aib dirinya; tidak kelihatan olehnya walaupun nyata. Kecil dipandangnya walaupun bagaimana besarnya.

$$
\text { - Jalinus At Thabib - }
$$

Untuk itu, menirulah, karena meniru adalah jalan terpendek untuk menjadikan diri Anda sama dengan pribadi yang Anda kagumi.

$$
\text { - Mario Teguh - }
$$

